that is, vital capacity, positive breath holding time, resting pulse rate and blood pressure were selected for the study. Pre- and post-test data on selected physiological variables were recorded prior to and after completion of 6 weeks pranayama training of experimental group, and the control group did not participate in the training programme. The criterion measures for measuring vital capacity was measured with Recorder and Medicare Systems Spirometer (Helios 401) in litres, positive breath holding and resting pulse rate was measured with the help of stopwatch, and blood pressure was measured by sphygmomanometer and stethoscope. Paired ' $t$ ' test statistical technique was employed to analyse the raw data, and the mean difference between the pretest and post-test scores each of the criterion variables of the groups. The level of significance was chosen at 0.05 level. From the findings it was observed that ' $t$ ' ratio was not significant in case of resting pulse rate and diastolic blood pressure. However in case of vital capacity and positive breath holding time ' $t$ ' was significant.

\title{
229 EFFECT OF UJJAYI AND BHASTRIKA PRANAYAMA ON SELECTED PHYSIOLOGICAL VARIABLES OF PHYSICALLY CHALLENGED STUDENTS
}

Indu Mazumdar, Avinash Suryavanshi Lakshmibai National University of Physical Education, Gwalior, Madhya Pradesh, India

\subsection{6/bjsm.2010.078725.229}

The purpose of the study was to analyse the effect of Ujjayi and Bhastrika Pranayama on selected physiological variables. For this 60 physically challenged male students were randomly selected as the subjects from Amar Jyoti School and Roshni Rehabilitation Centre, Gwalior. Further the subjects were divided into two groups that is, experimental group and control group. The experimental group followed of Ujjayi and Bhastrika Pranayama for a period of 6 weeks. The training was given for 5 days in a week in the morning. Only four physiological variables 